\title{
A Fuzzy Simulation-Based Optimization Approach for Groundwater Remediation Design at Contaminated Aquifers
}

\author{
A. L. Yang, ${ }^{1}$ G. H. Huang, ${ }^{1}$ Y. R. Fan, ${ }^{2}$ and X. D. Zhang $^{3}$ \\ ${ }^{1}$ MOE Key Laboratory of Regional Energy Systems Optimization, SEC Academy of Resource and \\ Environmental Research, North China Electric Power University, Beijing 102206, China \\ ${ }^{2}$ Faculty of Engineering and Applied Science, University of Regina, Regina, SK, Canada S4S 0A2 \\ ${ }^{3}$ Bureau of Economic Geology, Jackson School of Geosciences, \\ The University of Texas at Austin, Austin, TX 78713, USA
}

Correspondence should be addressed to G. H. Huang, guohhuang@gmail.com

Received 22 July 2011; Accepted 17 November 2011

Academic Editor: J. Jiang

Copyright (c) 2012 A. L. Yang et al. This is an open access article distributed under the Creative Commons Attribution License, which permits unrestricted use, distribution, and reproduction in any medium, provided the original work is properly cited.

A fuzzy simulation-based optimization approach (FSOA) is developed for identifying optimal design of a benzene-contaminated groundwater remediation system under uncertainty. FSOA integrates remediation processes (i.e., biodegradation and pump-and-treat), fuzzy simulation, and fuzzy-mean-value-based optimization technique into a general management framework. This approach offers the advantages of (1) considering an integrated remediation alternative, (2) handling simulation and optimization problems under uncertainty, and (3) providing a direct linkage between remediation strategies and remediation performance through proxy models. The results demonstrate that optimal remediation alternatives can be obtained to mitigate benzene concentration to satisfy environmental standards with a minimum system cost.

\section{Introduction}

Contaminated groundwater due to the spill and leakage of petroleum hydrocarbons may pose significant threats to local environment and human health. This provides an adequate reason for a great effort to remediate such contamination. Previously, many remediation methods (i.e., pump and treat, bioremediation, surfactant-enhanced aquifer remediation, etc.) were applied to mitigate groundwater contamination. However, many process variables in a groundwater remediation system, such as well location, pumping rate, oxygen-addition rate, and additive-addition rate, have significant impacts on the performance of remediation 
systems. The deficiency in understanding processes controlling the fate of contaminants may lead to a large inflation of expenses [1]. Simulation and optimization models were therefore developed in order to improve remediation efficiency [2].

Previously, many simulation and optimization methods were undertaken to identify effective groundwater remediation strategies [3-5]. Ahmad et al. [6] applied a response surface approach to a palm oil mill effluent treatment system for mitigating membrane fouling problems. Huang et al. [7] proposed an integrated numerical and physical modeling system to tackle natural attenuation and biodegradation processes for site remediation. He et al. [8] provided a coupled simulation-optimization approach for optimal design pumping rates of a pump-and-treat (PAT) system. However, most of previous simulation and optimization methods tended to focus on one fixed remediation technique, leading to relatively low efficiencies or high costs. For example, bioremediation via anaerobic dechlorination would not be an instantaneous process, which required time to develop the appropriate environmental conditions and to grow a microbial population (i.e., the capable degradation time may be several months to years) [9]; PAT might require significant costs for continuous pumping and extraction, as well as system maintenance; in detail, the operation cost of PAT would be 3 times higher than bioremediation [10]. Therefore, it is essential to develop simulation and optimization system for integrated remediation alternatives to enhance the remediation efficiency and reduce system cost.

Due to the difficulties in incorporating the complicated numerical simulation model within an optimization framework [11], a series of effective surrogates were applied to replace complex simulation equations [12-14]. Moreover, uncertainties may extensively exist in process forecasting (i.e., measurement and/or estimation errors related to hydrogeological and physicochemical parameters), which may significantly increase the complexity related to remediation design [15]. In the past decades, many stochastic theories were applied to optimal groundwater remediation design under uncertainty [16-19]. However, high computational cost and amounts of data requirement in stochastic analysis may constrict its application to some practical groundwater remediation problems. Consequently, fuzzy set theory has been used as an supplementary tool for many groundwater remediation optimization problems [20]. Guan and Aral [21] used fuzzy sets and optimization algorithms to optimize design of a PAT system under uncertainty. Nasiri et al. [22] developed a decision support system for the prioritization of remediation options based on the estimated compatibility index. The system combined fuzzy sets theory, environmental risk assessment with compatibility analysis procedure, which can be used to find a better remediation technology. Kerachian et al. [23] proposed a fuzzy game theoretic approach for groundwater resources management, which combined groundwater simulation models with the optimization model. Nonetheless, there are few considerations for identifying integrated groundwater remediation strategies (such as using PAT and bioremediation simultaneously) under uncertainty.

In this paper, a fuzzy simulation-based optimization approach (FSOA) is developed for identifying optimal remedial strategies for a petroleum-contaminated site. The objective entails the following tasks: (i) providing a fuzzy simulation model for biodegradation and PAT remediation processes, (ii) carrying out the model for generating a number of statistical samples, (iii) developing a fuzzy-mean-value-based optimization technique, and (iv) applying the proposed method to a petroleum-contaminated site for demonstration. 


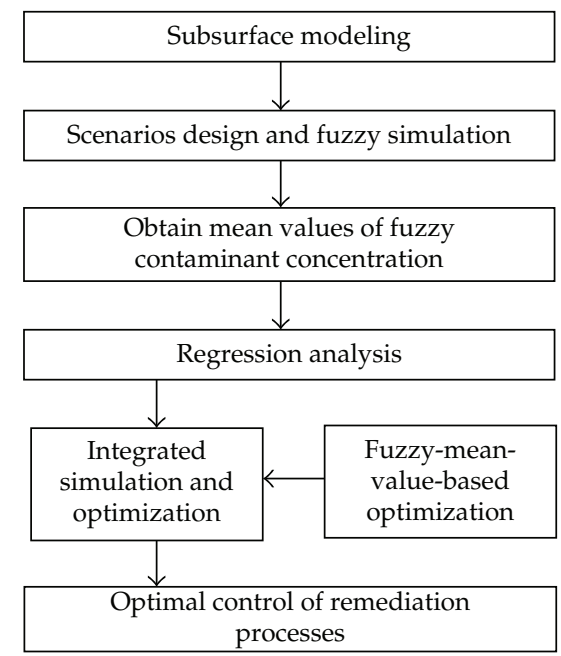

Figure 1: Integrated simulation and optimization framework for remediation-process control.

\section{Methodology}

FSOA consists of two major components: (2.1) fuzzy simulation and (2.2) fuzzy-mean-valuebased optimization. The framework of FSOA is shown in Figure 1. The fuzzy simulation component is used to predict contaminant transport under various remediation scenarios. The obtained contaminant concentrations are presented as fuzzy sets. Then the mean values of these fuzzy contaminant concentrations are obtained and applied to establish a set of surrogates for providing a bridge between remediation strategies (pumping rates at the wells) and contaminant concentrations. Finally a nonlinear optimization method is advanced by incorporating the surrogates into an optimization framework to identify optimal remediation strategies. The detailed procedures are described in the following sections.

\subsection{Stimulation Model}

\subsubsection{Stimulation of Contaminant Transport Process}

In this study, BIOPLUME III is used to simulate organic contaminants transport processes in groundwater, which has been used in many studies [10, 24, 25]. The mass transport equations are solved to calculate the spatial variation of the contaminant concentration [26]. In biodegradation processes, the aerobic biodegradation using oxygen as electron acceptors is simulated as an instantaneous reaction. The general equations are as follows [27]:

$$
\begin{gathered}
\frac{\partial(b H)}{\partial t}=\frac{1}{R_{h}}\left[\frac{\partial}{\partial x_{i}}\left(b D_{i j} \frac{\partial H}{\partial x_{j}}\right)-\frac{\partial\left(b H V_{i}\right)}{\partial x_{i}}\right]-\frac{H^{\prime} W}{n}-\frac{Q}{n} \delta\left(x-x^{(r)}\right) H, \\
\frac{\partial P b}{\partial t}=\left[\frac{\partial}{\partial x_{i}}\left(b D_{i j} \frac{\partial P}{\partial x_{j}}\right)-\frac{\partial\left(b P V_{i}\right)}{\partial x_{i}}\right]-\frac{P^{\prime} W}{n}
\end{gathered}
$$




$$
\begin{gathered}
\Delta H_{s o}=\frac{P}{F_{O}}, \quad P=0 \quad \text { if } H>\frac{P}{F_{O}}, \\
\Delta P_{o s}=H F_{O}, \quad H=0 \quad \text { if } P>H F_{O}, \\
\left.H(x, y, t)\right|_{t=0}=H_{0}(x, y), \quad(x, y) \in \Omega, t=0, \\
\left.H(x, y, t)\right|_{t=\Gamma 1}=H_{1}(x, y, t), \quad(x, y) \in \Gamma_{1}, t \geq 0,
\end{gathered}
$$

where $P$ is the concentration of oxygen $\left[\mathrm{M} / \mathrm{L}^{3}\right] ; P^{\prime}$ is the concentration of oxygen in source or sink fluid $\left[\mathrm{M} / \mathrm{L}^{3}\right] ; Q$ is the pumping rate $\left[\mathrm{L}^{3} / \mathrm{T}\right] ; x^{(r)}$ is the coordinates of the well; $\Delta H_{\text {so }}$ is the loss of the contaminant concentration due to aerobic biodegradation; $\Delta P_{O S}$ is the concentration loss of the electron acceptor; $F_{O}$ is the stoichiometric ratio for oxygen; $\Omega$ is the study domain; $\Gamma_{1}$ is the first boundary condition.

\subsubsection{Fuzzy Simulation}

In the past decades, the increasing awareness for uncertainties of porous media led to an improved understanding of contaminant transport in subsurface [14]. Fuzzy set theory is widely used for addressing uncertainties derived from vagueness in input parameters of subsurface models $[28,29]$. The primary procedures of fuzzy simulation are as follows [24]: (1) discretize the range of membership grade [0,1] into a number of $\alpha$-cut levels; (2) select an alpha-cut level for fuzzy inputs and generate $2^{m}$ combinatorial arrays for the input vector through fuzzy vertex analysis, where $m$ is the number of fuzzy parameters; (3) use the $2^{m}$ new vectors as inputs for the simulation model and generate $2^{m}$ outputs; (4) assign the smallest and largest values of outputs to the lower and upper limits, respectively; and (5) return to process 2 to assign other $\alpha$-cut levels and repeat processes 3 and 4 . The fuzzy sets of the predicted items are finally approximated based on the obtained lower and upper boundaries of simulation outputs under various $\alpha$-cut levels.

\subsection{Optimization Model}

\subsubsection{Fuzzy Regression Analysis}

In this subsection, regression analysis is used for studying the relationships between the response $(y)$ (i.e., contaminants concentrations) and a number of input variables $\left(x_{i}\right)$ (i.e., pump and injection rates). Considering the uncertainty of the outputs from the simulation model, a fuzzy regression analysis method is proposed to build relationships between contaminants concentrations and control variables. Then these relationships are used as constraints in the optimization framework.

Fuzzy regression analysis method consists of four stages, including (i) generating solutions through fuzzy simulation model, (ii) obtaining the mean values of the outputs, based on the method proposed by Fortemps and Roubens [30], (iii) fitting the inputs and outputs through a general polynomial regression analysis, and (iv) testing the predicting performance of the surrogates. If the surrogates have satisfactory performances, they can be used for substituting the numerical simulation model in further optimization framework. 


\subsubsection{Fuzzy-Mean-Value-Based Optimization}

In a groundwater remediation system, the installation cost can be generally neglected since it would be significantly less than well operation cost [31]. In addition, most costs for a remediation system are mainly functions of well pumping rates. Therefore, in this paper, the total pumping rate is used as decision variables of the optimization model, which will be minimized subject to environmental and economical constraints in order to obtain a minimum cost for the groundwater remediation system. The constraints of the optimization model include (i) contaminant concentrations at some locations, which should be less than or equal to a regulated environmental standard; (ii) the injection and extraction rates, which would be limited within a desired range; and (iii) water balance constraint, meaning that the sum of pumping rates at all extraction wells should be equal to the sum of injection rates at all injection wells. So, the optimization model can be formulated as follows [8]:

$$
\begin{aligned}
& \text { Minimize } f=A \times \sum_{i=1}^{I} Q_{i}^{\mathrm{In}}+B \times \sum_{j=1}^{J} Q_{j}^{\mathrm{Ex}} \\
& \text { subject to } C_{k}\left(Q_{i}^{\mathrm{In}}, Q_{j}^{\mathrm{Ex}}\right) \leq C_{\max }, \quad k=1,2, \ldots, K, \\
& \qquad \sum_{i=1}^{I} Q_{i}^{\mathrm{In}}=\sum_{j=1}^{J} Q_{j}^{\mathrm{Ex}}, \\
& 0 \leq Q_{i}^{\mathrm{In}} \leq Q_{i, \text { max }}^{\mathrm{In}} \quad i=1,2, \ldots, I, \\
& 0 \leq Q_{j}^{\mathrm{Ex}} \leq Q_{j, \text { max }}^{\mathrm{Ex}}, \quad j=1,2, \ldots, J,
\end{aligned}
$$

where $f$ is the total pumping/extraction cost; $A$ and $B$ are the unit injection and extraction cost, respectively; $Q_{i}^{\text {In }}$ and $Q_{j}^{\text {Ex }}$ are the pumping rates for the $i$ th injection well and $j$ th extraction well, respectively; $Q_{i, \max }^{\mathrm{In}}$ and $Q_{j, \max }^{\mathrm{Ex}}$ are the maximum pumping rates for the $i$ th injection well and $j$ th extraction well; $C_{\max }$ is the maximum acceptable contaminant concentration; $C_{k}$ is the expected contaminant concentration of $k$ th monitoring well after remediation. $C_{k}$ can be regarded as a polynomial function of injection/extraction rates $(Q 1, Q 2, \ldots, Q n)$. The surrogate can be formulated as follows:

$$
C_{k}=\beta_{0, k}+\sum_{i=1}^{n} \beta_{i, k} Q_{i}+\sum_{i=1}^{n} \sum_{j=1}^{n} \beta_{i j, k} Q_{i} Q_{j} \quad(i \neq j)
$$

where $\beta_{0, k}$ is an intercept term of surrogate $k ; \sum_{i=1}^{n} \beta_{i, k} Q_{i}$ are linear terms of surrogate $k$; $\sum_{i=1}^{n} \sum_{j=1}^{n} \beta_{i j, k} Q_{i} Q_{j}(i \neq j)$ are interaction terms of surrogate $k ; n$ is the number of explanatory variables. 
Table 1: Parameters of the simulation model.

\begin{tabular}{lc}
\hline Input parameter & Values \\
\hline Grid size & $20 \times 20$ \\
Cell size & $100 \times 100 \mathrm{ft}$ \\
Hydraulic conductivity & $6.56 \times 10^{-4} \mathrm{ft} / \mathrm{sec}$ \\
Hydraulic gradient & 0.005 \\
Retardation factor & 1.0 \\
Anisotropy factor & 1.0 \\
Background concentration of oxygen & $1 \mathrm{ppm}$ \\
Storage coefficient & 0.2 \\
Longitudinal dispersivity & Support $=(11,19)$, Core $=15$ \\
Transverse dispersivity & Support $=(1.1,1.9)$, Core $=1.5$ \\
Effective porosity & Support $=(0.2,0.4)$, Core $=0.3$ \\
\hline
\end{tabular}

\section{Case Study}

\subsection{Overview of the Study Site}

The developed FSOA model is applied to a hypothetical petroleum-contaminated aquifer (see Figure 2). The contaminated plume is assumed to be produced by a leaking underground storage tank (UST). The aquifer system of the site is unconfined, homogeneous, and anisotropy. The stratigraphy consists of sand with the depth varied within 13 and $20 \mathrm{ft}$ from the surface. The base of the aquifer ranges in elevation from about -3 to $-7 \mathrm{ft}$, and the groundwater flow direction is northeastwards with a gradient of approximate 0.005 . The horizontal hydraulic conductivity across the entire grid is $6.56 \times 10^{-4} \mathrm{ft} / \mathrm{sec}$, and the storage coefficient is about 0.2 . Table 1 shows parts of parameters. The previous UST was at the up gradient location of the site where the benzene concentration (approximate $16 \mathrm{mg} / \mathrm{L}$ ) in groundwater is higher than the regulated environmental guideline $(0.005 \mathrm{mg} / \mathrm{L})$ [32]. Thus, this site may pose impacts on surrounding communities and environment; remediation actions are desired for cleaning up contaminated groundwater.

The integration of PAT and biodegradation for remediating contaminated groundwater can be more efficient and cost-effective in comparison to simple PAT or biodegradation (as stated before). So, 2 injection (biodegradation), 4 (pump and treat) extraction, and 3 monitoring wells are constructed to inject nutrients for microorganism, install a PAT system, and monitor benzene concentrations, respectively. It is suggested that effective number of wells and their behaviors can improve remediation efficiency [33]. A simulationoptimization model is therefore an attractive tool for identifying optimal alternatives on these design components. However, since fuzzy uncertainty (as stated before) may exist in groundwater remediation design, fuzzy simulation-based optimization approach (FSOA) is desired for generating effective solution to address this issue.

\subsection{Results Analysis}

The simulation model is firstly run $m$ times to generate $m$ samples for further surrogates construction. In this study, 6 explanatory variables (pumping rates of the injection and extraction wells) and 3 response variables (expected contaminant concentrations at the monitoring wells M1 to M3) are interpreted by the surrogates. Within the range of pumping 


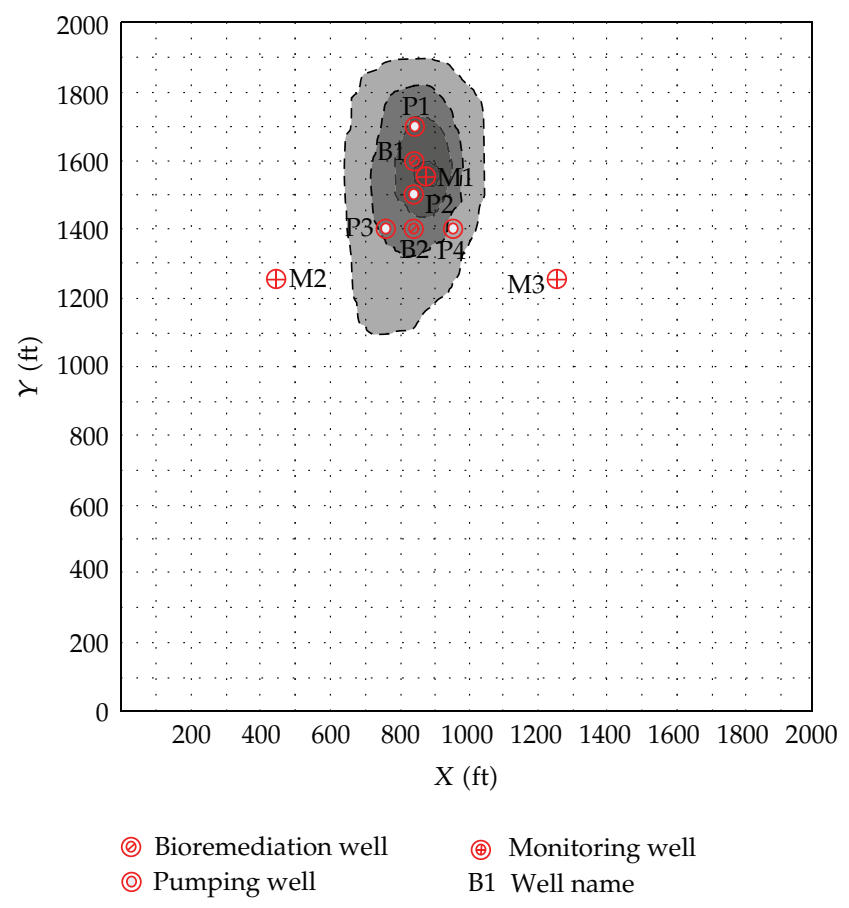

Figure 2: Simulation domain and well location.

rate between 0.0 and $0.08 \mathrm{ft}^{3} / \mathrm{sec}, 51$ scenarios of operation conditions (b1, b2, p1, p2, p3, and p4) are randomly generated (as listed in Table 2). Since some parameters of the system (e.g., porosity, dispersivity) are presented as fuzzy sets, a fuzzy simulation model is applied to deal with these uncertain parameters and generate contaminant concentrations under various operation scenarios. The outputs of the fuzzy simulation model are also presented as fuzzy sets. Therefore, a fuzzy regression method is applied to establish the surrogates between contaminant concentrations and operation variables.

Biodegradation injection rates (b1 and b2) in injection wells B1 and B2 and extraction rates (p1, p2, p3, and p4) in extraction wells P1, P2, P3, and P4 are selected as control variables to produce a series of operation scenarios. The benzene concentrations in monitoring wells are simulated during a 2-year remediation period under each operation condition. Figure 3 shows the results of expected benzene concentrations of wells M1, M2, and M3. It appears that different results are generated under different scenarios. Thus, it is worthwhile to identify the interactive relations between system operation patterns and contaminant concentrations, such that the trade-off between system cost and remediation efficiency can be analyzed.

Figure 4 presents the comparison of the results from fuzzy regression analysis and the mean value of benzene concentrations from numerical simulation. It is indicated that the fuzzy regression models can generally reflect the variation of benzene concentration under different operation scenarios. The peak values in three monitoring wells can be well caught. The RSME values of three models are $0.03114,0.102$, and 0.0532 , respectively. These results demonstrate that the established surrogates have satisfactory prediction accuracy.

A nonlinear optimization model is then developed to identify the optimal operating conditions. When the maximum concentration standard is set as $0.001 \mathrm{mg} / \mathrm{L}$, the injection rates in wells b1 and b2 are 0.0 and $0.0499 \mathrm{ft}^{3} / \mathrm{s}$, respectively; the extraction rates are 
Table 2: Scenarios of flow rates in injection and extraction wells $\left(\mathrm{ft}^{3} / \mathrm{sec}\right)$.

\begin{tabular}{|c|c|c|c|c|c|c|}
\hline Scenario & $\mathrm{p} 1$ & b1 & $\mathrm{p} 2$ & $\mathrm{~b} 2$ & p3 & $\mathrm{p} 4$ \\
\hline 1 & 0.01 & 0.020 & 0.01 & 0.02 & 0.01 & 0.010 \\
\hline 2 & 0.015 & 0.030 & 0.015 & 0.03 & 0.015 & 0.015 \\
\hline 3 & 0.012 & 0.025 & 0.014 & 0.025 & 0.008 & 0.016 \\
\hline 4 & 0.009 & 0.010 & 0.021 & 0.058 & 0.018 & 0.020 \\
\hline 5 & 0.013 & 0.037 & 0.006 & 0.01 & 0.02 & 0.008 \\
\hline 6 & 0.02 & 0.049 & 0.018 & 0.036 & 0.029 & 0.018 \\
\hline 7 & 0.03 & 0.052 & 0.025 & 0.04 & 0.025 & 0.012 \\
\hline 8 & 0.006 & 0.044 & 0.028 & 0.016 & 0.021 & 0.005 \\
\hline 9 & 0.025 & 0.032 & 0.008 & 0.033 & 0.006 & 0.026 \\
\hline 10 & 0.029 & 0.042 & 0.017 & 0.045 & 0.032 & 0.009 \\
\hline 11 & 0.005 & 0.029 & 0.009 & 0.028 & 0.012 & 0.031 \\
\hline 12 & 0.007 & 0.035 & 0.013 & 0.038 & 0.021 & 0.032 \\
\hline 13 & 0.018 & 0.002 & 0.012 & 0.048 & 0.009 & 0.011 \\
\hline 14 & 0.026 & 0.057 & 0.018 & 0.018 & 0.011 & 0.020 \\
\hline 15 & 0.016 & 0.040 & 0.026 & 0.022 & 0.013 & 0.007 \\
\hline 16 & 0.021 & 0.042 & 0.019 & 0.029 & 0.017 & 0.014 \\
\hline 17 & 0.014 & 0.026 & 0.011 & 0.012 & 0.005 & 0.008 \\
\hline 18 & 0.019 & 0.034 & 0.007 & 0.019 & 0.014 & 0.013 \\
\hline 19 & 0.022 & 0.038 & 0.02 & 0.024 & 0.016 & 0.004 \\
\hline 20 & 0.024 & 0.008 & 0.005 & 0.032 & 0.007 & 0.004 \\
\hline 21 & 0.005 & 0.038 & 0.033 & 0 & 0 & 0.000 \\
\hline 22 & 0.033 & 0.031 & 0 & 0.021 & 0.019 & 0.000 \\
\hline 23 & 0.023 & 0.087 & 0.022 & 0 & 0.023 & 0.019 \\
\hline 24 & 0 & 0.008 & 0.016 & 0.06 & 0.035 & 0.017 \\
\hline 25 & 0.008 & 0.059 & 0.029 & 0.006 & 0.022 & 0.006 \\
\hline 26 & 0.004 & 0.003 & 0.021 & 0.08 & 0.03 & 0.028 \\
\hline 27 & 0.012 & 0.029 & 0.023 & 0.029 & 0.013 & 0.010 \\
\hline 28 & 0.02 & 0.041 & 0.016 & 0.031 & 0.021 & 0.015 \\
\hline 29 & 0.017 & 0.033 & 0.006 & 0.02 & 0.019 & 0.011 \\
\hline 30 & 0.008 & 0.026 & 0.011 & 0.025 & 0.011 & 0.021 \\
\hline 31 & 0.011 & 0.028 & 0.007 & 0.015 & 0.024 & 0.001 \\
\hline 32 & 0.016 & 0.055 & 0.021 & 0.032 & 0.038 & 0.012 \\
\hline 33 & 0.020 & 0.074 & 0.016 & 0.006 & 0.012 & 0.033 \\
\hline 34 & 0.029 & 0.072 & 0.028 & 0.060 & 0.036 & 0.039 \\
\hline 35 & 0.012 & 0.000 & 0.022 & 0.039 & 0.004 & 0.001 \\
\hline 36 & 0.004 & 0.024 & 0.007 & 0.022 & 0.003 & 0.033 \\
\hline 37 & 0.018 & 0.039 & 0.013 & 0.026 & 0.009 & 0.025 \\
\hline 38 & 0.019 & 0.023 & 0.005 & 0.061 & 0.037 & 0.022 \\
\hline 39 & 0.001 & 0.016 & 0.029 & 0.026 & 0.003 & 0.010 \\
\hline 40 & 0.027 & 0.076 & 0.011 & 0.005 & 0.011 & 0.033 \\
\hline 41 & 0.029 & 0.074 & 0.001 & 0.014 & 0.040 & 0.018 \\
\hline 42 & 0.011 & 0.072 & 0.023 & 0.003 & 0.008 & 0.033 \\
\hline 43 & 0.010 & 0.047 & 0.027 & 0.040 & 0.020 & 0.030 \\
\hline 44 & 0.028 & 0.056 & 0.009 & 0.009 & 0.012 & 0.016 \\
\hline 45 & 0.031 & 0.057 & 0.008 & 0.037 & 0.027 & 0.028 \\
\hline 46 & 0.022 & 0.038 & 0.028 & 0.078 & 0.038 & 0.028 \\
\hline 47 & 0.019 & 0.029 & 0.004 & 0.054 & 0.031 & 0.030 \\
\hline 48 & 0.036 & 0.080 & 0.028 & 0.026 & 0.027 & 0.016 \\
\hline 49 & 0.018 & 0.016 & 0.021 & 0.058 & 0.005 & 0.029 \\
\hline 50 & 0.032 & 0.033 & 0.025 & 0.043 & 0.004 & 0.015 \\
\hline 51 & 0.000 & 0.014 & 0.000 & 0.000 & 0.000 & 0.000 \\
\hline
\end{tabular}




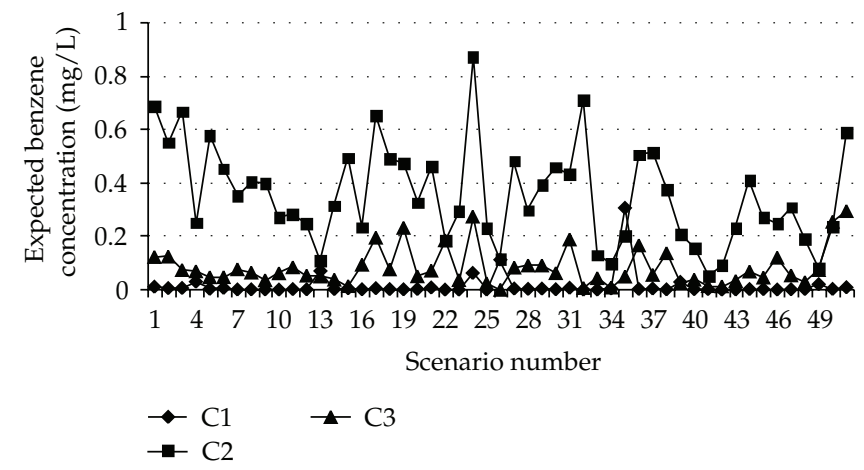

Figure 3: Expected benzene concentrations under 51 operation scenarios (on day 730).

$\mathrm{p} 1=0.027 \mathrm{ft}^{3} / \mathrm{s}, \mathrm{p} 2=0.0 \mathrm{ft}^{3} / \mathrm{s}, \mathrm{p} 3=0.0065 \mathrm{ft}^{3} / \mathrm{s}$, and $\mathrm{p} 4=0.0164 \mathrm{ft}^{3} / \mathrm{s}$. Under this standard, wells B2 and P1 would play more important role while wells P3 and P4 would have less contributions to contaminant reduction. When the maximum concentration standard is set as $0.004 \mathrm{mg} / \mathrm{L}$, the injection rates are $\mathrm{b} 1=0.0 \mathrm{ft}^{3} / \mathrm{s}$ and $\mathrm{b} 2=0.0492 \mathrm{ft}^{3} / \mathrm{s}$; the extraction rates are $\mathrm{p} 1=0.0267 \mathrm{ft}^{3} / \mathrm{s}, \mathrm{p} 2=0.0 \mathrm{ft}^{3} / \mathrm{s}, \mathrm{p} 3=0.0072 \mathrm{ft}^{3} / \mathrm{s}$, and $\mathrm{p} 4=0.0153 \mathrm{ft}^{3} / \mathrm{s}$. Comparing results between these two scenarios, the system is sensitive to variations of the maximum concentration standard. Under stricter standard, the remediation system should conduct larger pumping rates, which would enhance the remediation efficiency but accordingly cause the growth of remediation cost. Conversely, looser standard would lead to less pumping rates, which corresponds to low remediation cost and efficiency. Therefore, the developed method can help decision maker make a trade-off for the operation condition between system cost and efficiency under uncertainty.

\subsection{Discussions}

In this study, we consider parameters of soil porosity, longitudinal dispersivity, and transverse dispersivity as fuzzy sets due to insufficient data for specifying related probability density functions. Actually, fuzzy simulation can handle more fuzzy parameters. One should know that the uncertainty in output concentration increases as the number of uncertain parameters increases [24]. In addition to the performance of fuzzy simulation, the accuracy of optimization results also depends upon the surrogates used to represent the relationships between expected concentrations and pumping rates. A major concern is that approximation errors of surrogates may lead to large deviations of solutions. On one hand, this concern can be mitigated by using higher-order regression analysis based on large volumes of testing samples. On the other hand, the approximation accuracy may benefit from improvement of pretreatment method for uncertain outputs such as fuzzy expected value models [34,35].

For comparison, if uncertain parameters are defuzzified to generate related representative deterministic values before conducting simulation, the procedures of defuzzified simulation-based optimization approach (DSOA) can be obtained and generalized as follows: step 1, defuzzify parameters; step 2, generate a number of remediation scenarios; step 3 , compute the contaminant concentrations under the defuzzified parameters through the simulator; step 4, establish a set of surrogates for providing bridges between remediation strategies and contaminant concentrations; step 5, incorporate the surrogates into the optimization framework; and step 6, solve the optimization model. 


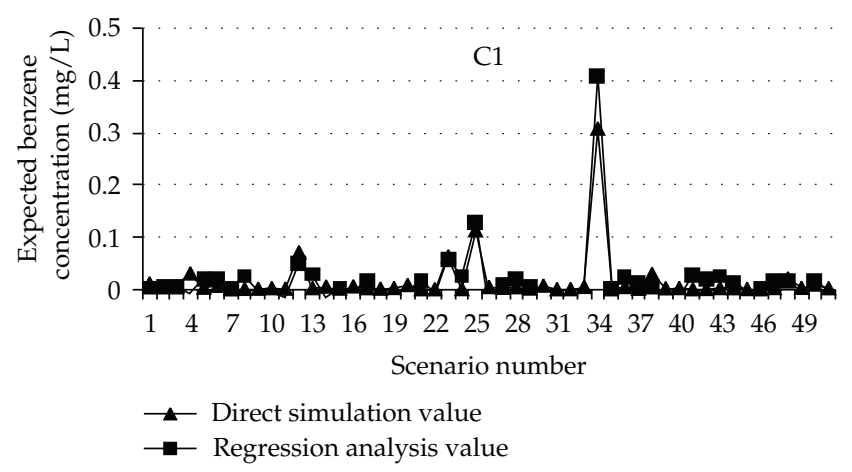

(a)

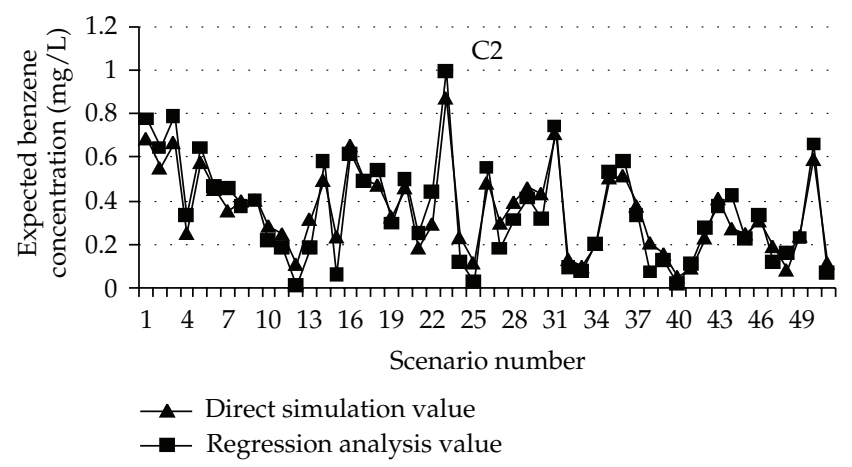

(b)

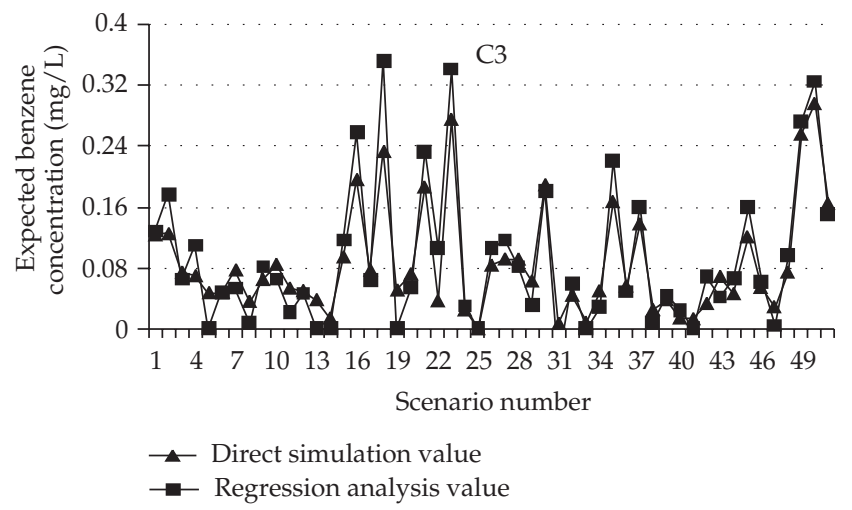

(c)

Figure 4: Regression analysis versus direct simulation in benzene concentrations.

Figure 5 presents mean values of benzene concentration obtained from FSOA versus DSOA at different monitoring wells. Both methods used triangular possibility distributions to present uncertainty. The results from DSOA and FSOA are similar with each other. However, to some extent, DSOA may take an obvious role in reduction of peak value. For example, the mean values of benzene concentrations obtained by DSOA may be $0.254,0.456$, and $0.138 \mathrm{mg} / \mathrm{L}$ at wells M1, M2, and M3, respectively (shown as red remarked). These values are lower than those obtained by FSOA $(0.3072,0.7115,0.2329)$. This indicates that DSOA may 


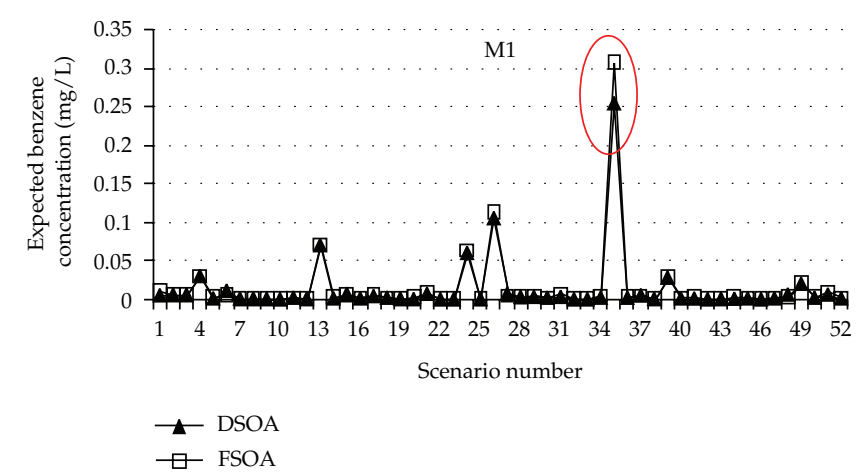

(a)

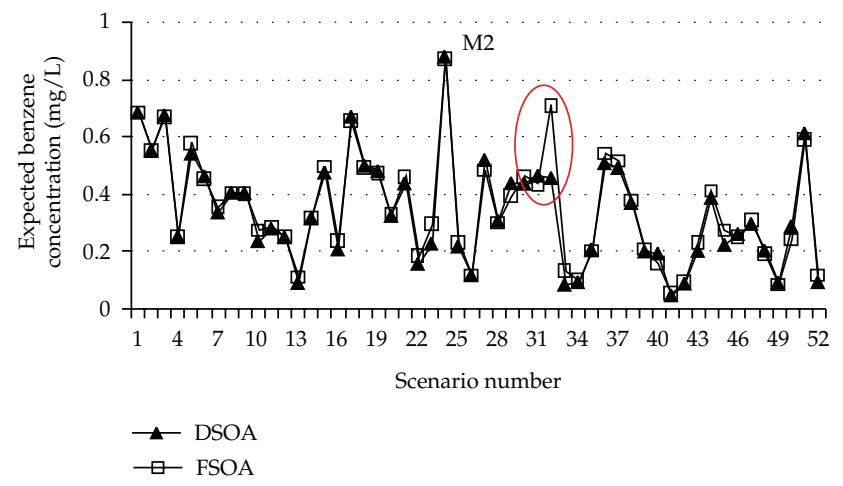

(b)

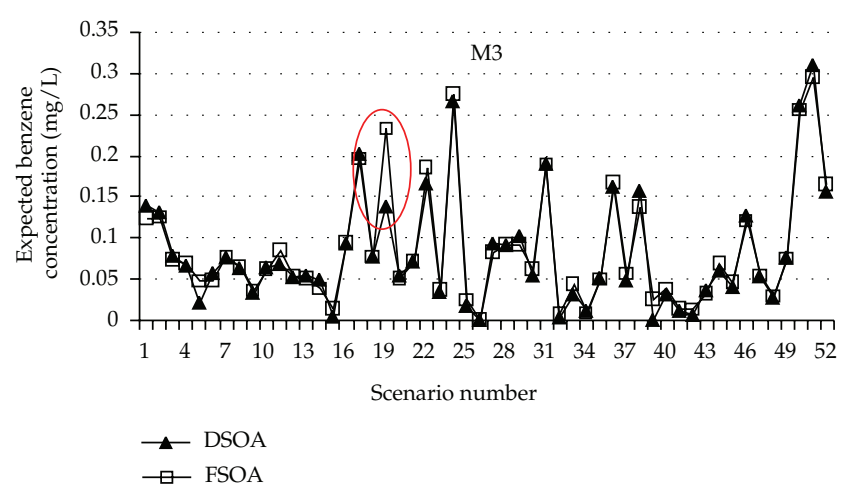

(c)

Figure 5: Simulation results by DSOA versus FSOA in benzene concentrations.

not well represent system uncertainty and may be too idealistic for the effect of remediation. In addition, defuzzification before simulation cannot well reflect the impact of uncertainty to the simulation model system.

\section{Conclusion}

In this paper, a fuzzy simulation-based optimization approach (FSOA) has been developed for supporting process control of remediation at petroleum-contaminated sites. FSOA 
integrated fuzzy simulation and fuzzy regression analysis method into a nonlinear optimization framework for generating desired operation conditions. The developed method was applied to a hypothetical petroleum-contaminated case study. FSOA can address the uncertainty of modeling parameters in simulating flow and transport of contaminants in groundwater and then generate optimal remediation strategies. The results can provide bases for guiding remediation performances. They are also useful for decision makers to analyze trade-offs between system cost and treatment efficiency.

\section{Acknowledgments}

This paper was supported by the Beijing Municipal Program of Technology Transfer and Industrial Application, and the Natural Sciences Foundation of China (No. 51190095).

\section{References}

[1] Z. Chen, G. H. Huang, and A. Chakma, "Numerical modeling soil and groundwater contaminationa study for petroleum-contaminated site," Tech. Rep., TransGas-SaskEnergy, Regina, Canada, 1998.

[2] L. He, G. H. Huang, and H. W. Lu, "A stochastic optimization model under modeling uncertainty and parameter certainty for groundwater remediation design-Part I. Model development," Journal of Hazardous Materials, vol. 176, no. 1-3, pp. 521-526, 2010.

[3] A. S. Mayer, C. T. Kelley, and C. T. Miller, "Optimal design for problems involving flow and transport phenomena in saturated subsurface systems," Advances in Water Resources, vol. 25, no. 8-12, pp. 12331256, 2002.

[4] D. A. Baú and A. S. Mayer, "Stochastic management of pump-and-treat strategies using surrogate functions," Advances in Water Resources, vol. 29, no. 12, pp. 1901-1917, 2006.

[5] X. S. Qin, "Assessing environmental risks through fuzzy parameterized probabilistic analysis," Stochastic Environmental Research and Risk Assessment, vol. 26, no. 1, pp. 43-58, 2011.

[6] A. L. Ahmad, S. Ismail, and S. Bhatia, "Optimization of coagulation-flocculation process for palm oil mill effluent using response surface methodology," Environmental Science and Technology, vol. 39, no. 8, pp. 2828-2834, 2005.

[7] Y. F. Huang, G. H. Huang, G. Q. Wang, Q. G. Lin, and A. Chakma, "An integrated numerical and physical modeling system for an enhanced in situ bioremediation process," Environmental Pollution, vol. 144, no. 3, pp. 872-885, 2006.

[8] L. He, G. H. Huang, H. W. Lu, and G. M. Zeng, “Optimization of surfactant-enhanced aquifer remediation for a laboratory BTEX system under parameter uncertainty," Environmental Science and Technology, vol. 42, no. 6, pp. 2009-2014, 2008.

[9] H. Stroo, H. C. Ward, and B. C. Alleman, In Situ Remediation of Chlorinated Solvent Plumes, Springer Sciences and Business Media, New York, NY, USA, 2010.

[10] H. J. Shieh and R. C. Peralta, "Optimal in situ bioremediation design by hybrid genetic algorithmsimulated annealing," Journal of Water Resources Planning and Management, vol. 131, no. 1, pp. 67-78, 2005.

[11] Y. F. Huang, Development of environmental modeling methodologies for supporting system simulation, optimization and process control in petroleum waste management, Ph.D. thesis, University of Regina, Regina, Canada, 2004.

[12] G. H. Huang, J. B. Li, and I. Maqsood, Numerical Simulation, Risk Assessment, Site Remediation, and Monitoring Design-A Study of Soil and Groundwater Contamination at the Cantuar Field Scrubber Site Prepared for Environmental Affairs, TransGas-SaskEnergy, 2003.

[13] S. Yan and B. Minsker, "Optimal groundwater remediation design using an Adaptive Neural Network Genetic Algorithm," Water Resources Research, vol. 42, no. 5, Article ID W05407, 14 pages, 2006.

[14] L. He, G. H. Huang, G. M. Zeng, and H. W. Lu, “An integrated simulation, inference, and optimization method for identifying groundwater remediation strategies at petroleum-contaminated aquifers in western Canada," Water Research, vol. 42, no. 10-11, pp. 2629-2639, 2008.

[15] X. S. Qin and Y. Xu, "Analyzing urban water supply through an acceptability-index-based interval approach," Advances in Water Resources, vol. 34, no. 7, pp. 873-886, 2011. 
[16] D. A. Baú and A. S. Mayer, "Stochastic management of pump-and-treat strategies using surrogate functions," Advances in Water Resources, vol. 29, no. 12, pp. 1901-1917, 2006.

[17] A. Mantoglou and G. Kourakos, "Optimal groundwater remediation under uncertainty using multiobjective optimization," Water Resources Management, vol. 21, no. 5, pp. 835-847, 2007.

[18] Y. Xu and X. S. Qin, "Agricultural effluent control under uncertainty: an inexact double-sided fuzzy chance-constrained model," Advances in Water Resources, vol. 33, no. 9, pp. 997-1014, 2010.

[19] S. Yan and B. Minsker, "Applying dynamic surrogate models in noisy genetic algorithms to optimize groundwater remediation designs," Journal of Water Resources Planning and Management, vol. 137, no. 3, pp. 284-292, 2011.

[20] G. H. Huang and N. B. Chang, "The perspectives of environmental informatics and systems analysis," Journal of Environmental Informatics, vol. 1, no. 1, pp. 1-7, 2003.

[21] J. Guan and M. M. Aral, "Optimal design of groundwater remediation systems using fuzzy set theory," Water Resources Research, vol. 40, no. 1, Article ID W01518, 20 pages, 2004.

[22] F. Nasiri, G. Huang, and N. Fuller, "Prioritizing groundwater remediation policies: a fuzzy compatibility analysis decision aid," Journal of Environmental Management, vol. 82, no. 1, pp. 13-23, 2007.

[23] R. Kerachian, M. Fallahnia, M. R. Bazargan-Lari, A. Mansoori, and H. Sedghi, "A fuzzy game theoretic approach for groundwater resources management: application of Rubinstein Bargaining Theory," Resources, Conservation and Recycling, vol. 54, no. 10, pp. 673-682, 2010.

[24] R. K. Prasad and S. Mathur, "Health-risk-based remedial alternatives for contaminated aquifer management," Practice Periodical of Hazardous, Toxic, and Radioactive Waste Management, vol. 14, no. 1, pp. 61-69, 2010.

[25] M. P. Suarez and H. S. Rifai, "Modeling natural attenuation of total BTEX and benzene plumes with different kinetics," Ground Water Monitoring and Remediation, vol. 24, no. 3, pp. 53-68, 2004.

[26] H. S. Rifai, C. J. Newell, J. R. Gonzales, S. Dendrou, L. Kennedy, and J.T. Wilson, BIOPLUME III Natural Attenuation Decision Support System, Version 1.0 User's Manual, Air Force Center for Environmental Excellence (AFCEE), San Antonio, Tex, USA, 1997.

[27] R. C. Borden and P. B. Bedient, "Transport of dissolved hydrocarbons influenced by oxygen-limited biodegradation: 1. Theoretical development," Water Resources Research, vol. 22, no. 13, pp. 1973-1982, 1986.

[28] X. Qin, Y. Xu, and J. Su, "Municipal solid waste-flow allocation planning with trapezoidal-shaped fuzzy parameters," Environmental Engineering Science, vol. 28, no. 8, pp. 573-584, 2011.

[29] B. D. Xi, X. S. Qin, X. K. Su, Y. H. Jiang, and Z. M. Wei, "Characterizing effects of uncertainties in MSW composting process through a coupled fuzzy vertex and factorial-analysis approach," Waste Management, vol. 28, no. 9, pp. 1609-1623, 2008.

[30] P. Fortemps and M. Roubens, "Ranking and defuzzification methods based on area compensation," Fuzzy Sets and Systems, vol. 82, no. 3, pp. 319-330, 1996.

[31] B. S. Minsker and C. A. Shoemaker, "Dynamic optimal control of in-situ bioremediation of ground water," Journal of Water Resources Planning and Management, vol. 124, no. 3, pp. 149-161, 1998.

[32] SERM (Saskatchewan Environment and Resource Management), Risk Based Corrective Actions for Petroleum Contaminated Sites, Province of Saskatchewan, Regina, Canada, 1999.

[33] C. S. Sawyer and M. Kamakoti, "Optimal flow rates and well locations for soil vapor extraction design," Journal of Contaminant Hydrology, vol. 32, no. 1-2, pp. 63-76, 1998.

[34] B. Liu and Y.-K. Liu, "Expected value of fuzzy variable and fuzzy expected value models," IEEE Transactions on Fuzzy Systems, vol. 10, no. 4, pp. 445-450, 2002.

[35] L. G. Shao, X. S. Qin, and Y. Xu, "A conditional value-at-risk based inexact water allocation model," Water Resources Management, vol. 25, no. 9, pp. 2125-2145, 2011. 


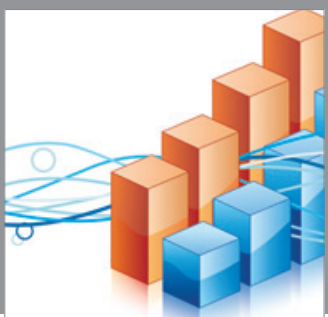

Advances in

Operations Research

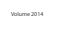

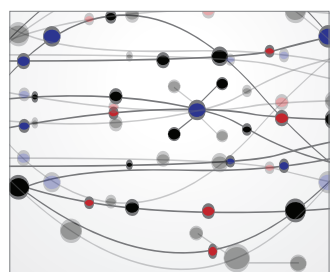

\section{The Scientific} World Journal
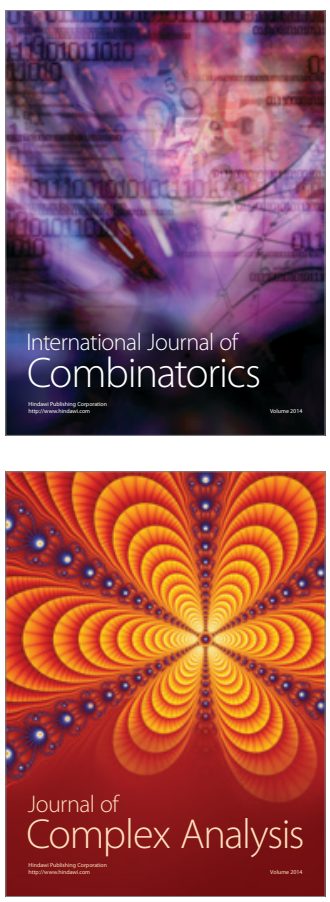

International Journal of

Mathematics and

Mathematical

Sciences
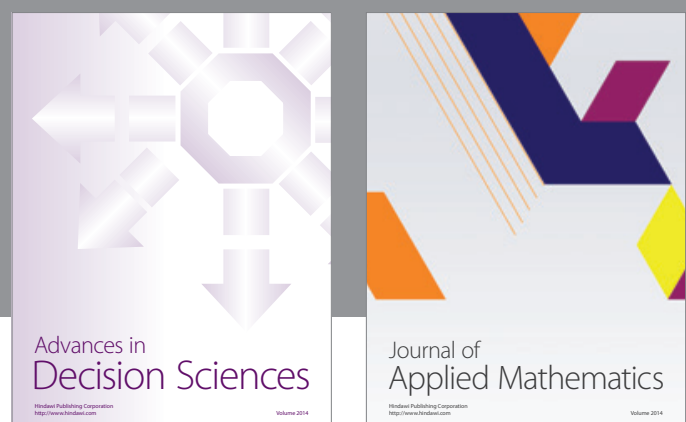

Journal of

Applied Mathematics
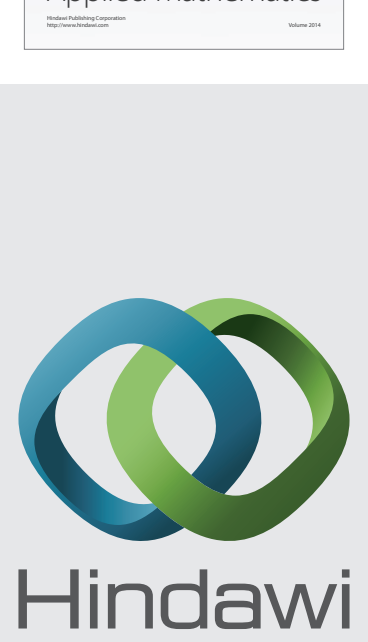

Submit your manuscripts at http://www.hindawi.com
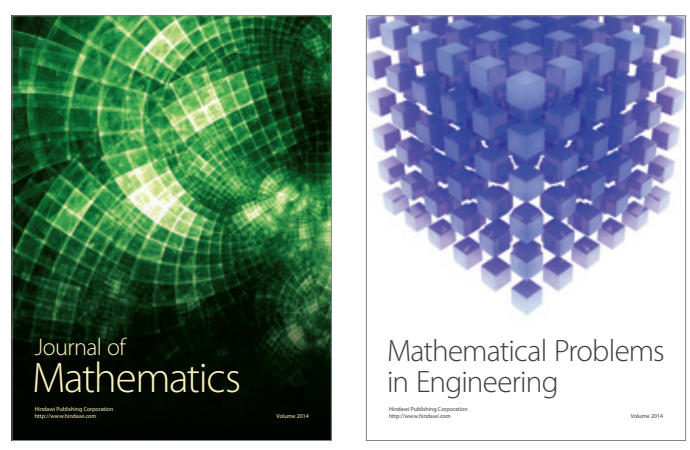

Mathematical Problems in Engineering
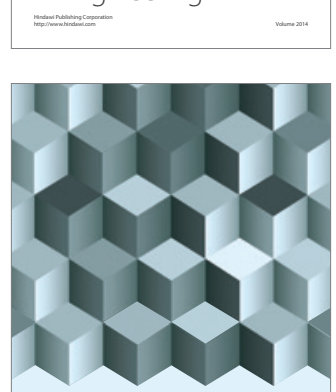

Journal of

Function Spaces
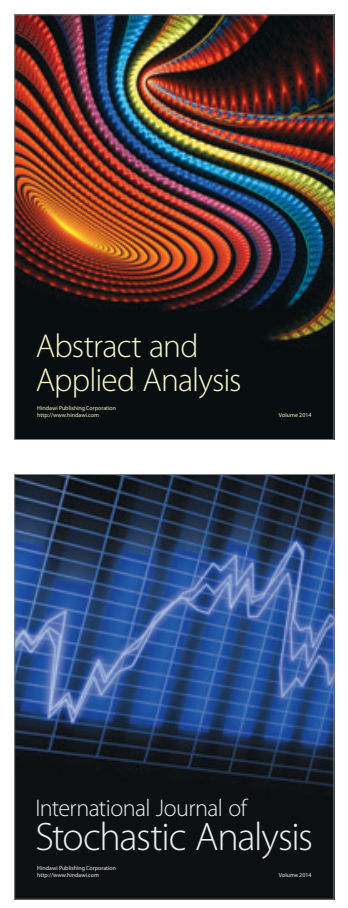

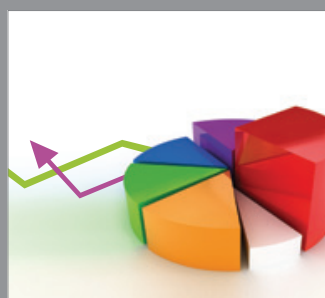

ournal of

Probability and Statistics

Promensencen
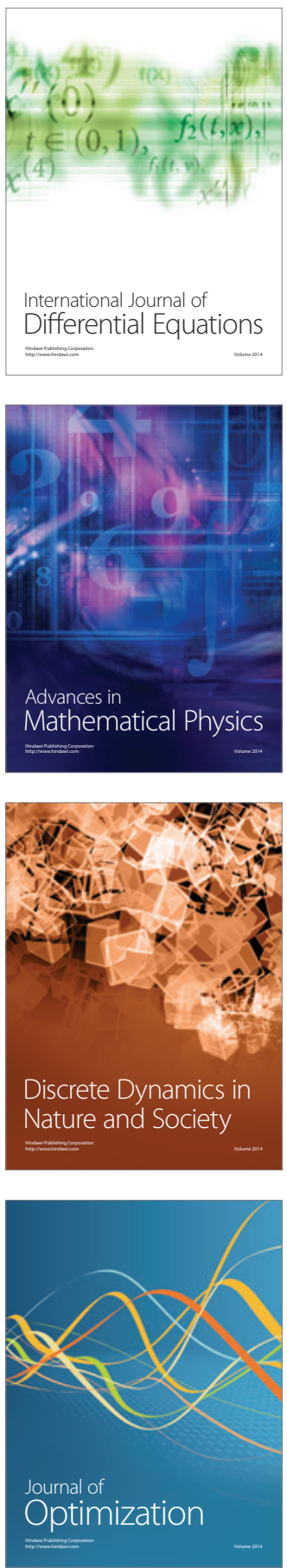